\title{
Conscious Clinical Education: The Evidence-Based Education-Clinical Education Model
}

\author{
Mark DeRuiter, M.B.A., Ph.D., CCC-A/SLP ${ }^{1}$ and \\ Sarah M. Ginsberg, Ed.D., CCC-SLP²
}

The fields of speech-language pathology and audiology, collectively referred to as communication sciences and disorders, are driven by evidence-based practice (EBP). As accountability in clinical service delivery continues to increase, there are few who would argue that encouraging clinicians to engage in methods that have withstood the rigors of peer-review is the wrong approach. Graduate students are typically given many opportunities to learn about the evidence for their discipline, and graduate programs are required to provide these opportunities under accreditation standards. While EBP is critical to our discipline's clinical function, we assert that evidence-based education (EBE) is equally as important as EBP to our discipline's function in educating our students. This article discusses EBP and EBE with a focus on elements that may not have been considered in the past, particularly within the complex dynamic of the EBE and clinical education interface. We present current and proposed models, including a new model of EBE in clinical education. We share insights into how the new and proposed models fit within the broader context of clinical decision making and the scholarship of teaching and learning. We conclude by addressing future needs for the education of clinical educators.

KEYWORDS: clinical education, evidence-based practice, communication sciences and disorders, scholarship of teaching and learning, evidence-based education

${ }^{1}$ Department of Speech, Language, and Hearing Sciences, University of Arizona, Tucson, Arizona; ${ }^{2}$ Department of Special Education and Communication Sciences and Disorders, Eastern Michigan University, Ypsilanti, Michigan.

Address for correspondence: Mark DeRuiter, M.B.A., Ph.D., CCC-A/SLP, Department of Speech, Language, and Hearing Sciences, University of Arizona, 1131 E. Second Street, Tucson, AZ 85721

(e-mail: mderuiter@email.arizona.edu).
Supervision of Students in Clinical Practice: A Focus on Competency-Based Education Approaches; Guest Editor, Patrick R. Walden, Ph.D., CCC-SLP

Semin Speech Lang 2020;41:279-288. Copyright (C) 2020 by Thieme Medical Publishers, Inc., 333 Seventh Avenue, New York, NY 10001, USA. Tel: +1(212) 7600888 .

DOI: https://doi.org/10.1055/s-0040-1713779.

ISSN 0734-0478. 
Learning Outcomes: As a result of this activity, the reader will be able to (1) describe the evidence-based education — clinical education model; (2) list three hidden factors related to clinical providers in the clinical education model; and (3) describe key differences among good clinical education, scholarly clinical education, and the scholarship of teaching and learning for the clinical educator.

As described by the American SpeechLanguage-Hearing Association (ASHA), evidence-based practice (EBP) means that as communication sciences and disorders (CSD) professionals, we look to three sources of knowledge to inform our clinical decision making: knowledge of the patients' needs; highquality evidence-based scientific and clinical practice literature that has been made available through public dissemination; and knowledge developed from our professional experiences that allows us to apply the literature appropriately. ${ }^{1-3}$ These three sources are discussed in the context of a triangulated model that is widely familiar in our discipline. The value of EBP is that it gives us guiding standards to rely on in making clinical decisions. Thus, rather than relying solely on what the patient would prefer or what our instinct tells us, we must find the intersection between what the literature tells us is effective, the patient's perspectives, and our professional judgment about achieving the best outcomes. The ultimate goal of EBP is always to maximize the patient's success, and for the clinician to consciously engage in the process of EBP for every patient seen in their practice.

The triangulated EBP model was adapted for higher education in 2012 to address the need for a quality foundation on which to structure classroom teaching for CSD higher education programs. Much like the EBP model is used to guide clinical practice, the resulting evidencebased education (EBE) model asserts that critical elements should guide conscious decisionmaking processes as CSD faculty are teaching CSD students. ${ }^{4}$ The three key elements for the EBE model parallel the elements of the EBP model. Where EBP focuses on the clinician's knowledge of patient preferences, the teacherlearner interaction in EBE focuses on the higher education instructor's understanding of their relationship with the learner and the learner's experiences and needs. Where EBP addresses the clinician's knowledge based on professional experience, EBE gives value to the instructor's knowledge of the content and their insights into the most effective way to teach it for optimal student learning experiences. Shulman referred to this body of knowledge that instructors hold as pedagogical content knowledge (PCK). ${ }^{5} \mathrm{Fi}-$ nally, external scientific evidence, used in the EBP model to describe the body of literature that demonstrates effectiveness of clinical methods, is represented in the EBE model as the scholarship of teaching and learning (SoTL). SoTL work has been peer-reviewed and serves to demonstrate the effectiveness of proven methods of teaching that improve student learning. SoTL literature may originate from CSD or it may come from related disciplines, such as nursing, psychology, and education. Just as the ultimate goal of EBP is to ensure the greatest likelihood of patient success, the goal of $\mathrm{EBE}$ is to ensure the greatest likelihood of student success-learning. Fig. 1 reflects the intersection of PCK, SoTL, and instructor-learner interaction insights that represent EBE.

The value of EBE in higher education is fully realized when faculty who consider this model are encouraged to move away from a fixed thinking of "what has always worked" or "this is how I was taught" and toward an evidence-based pedagogy. The use of EBE guides instructors toward developing their professional knowledge and judgment regarding how valuable a method of teaching will be to the students' learning. EBE also helps instructors consciously balance the discrepancies between what we know the students like or enjoy and what is in their best interest for significant learning. The reliance on EBE moves us from uninformed decision-making toward evidencebased decisions. EBE is the backbone of a wellreasoned and effective learning experience for our students. As instructors, it is vital that we make the most of our time and effort, as well as the students' time and effort, to help them develop into the most effective clinicians possible for their patients. 


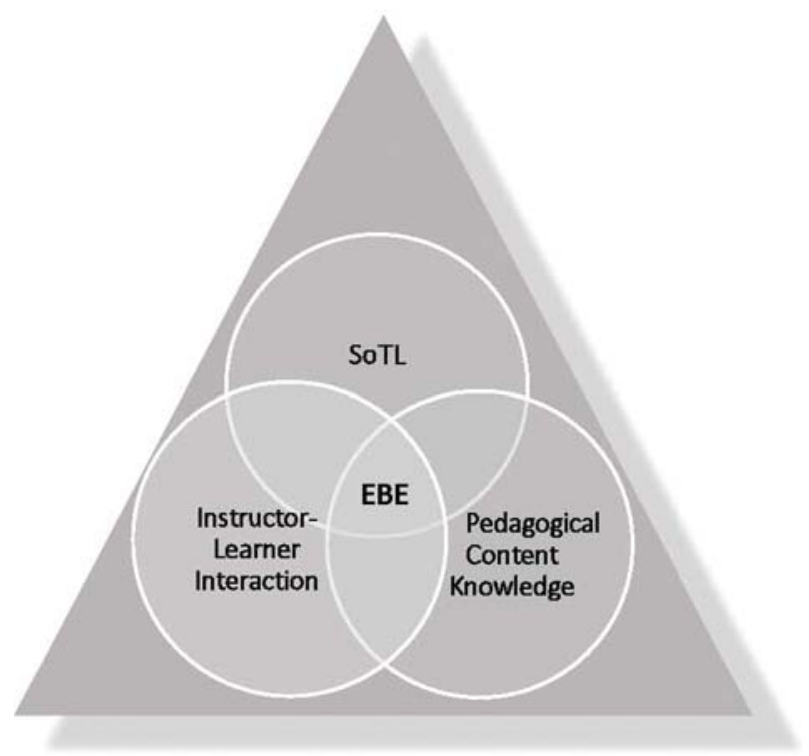

Figure 1 Evidence-based education (EBE) model. ${ }^{4}$ SoTL, scholarship of teaching and learning.

THE USE OF EVIDENCE IN CSD: A CLINICAL EDUCATION MODEL

Until very recently, there has not been a way to conceptualize the process by which clinical educators and supervisors (referred to as clinical educators, or CEs, henceforth) consciously and simultaneously mediate:

- The preferences of those they work with (students and patients/clients).

- Their understanding of the literature (EBP and EBE).

- Their own professional experiences.

Therefore, we proposed a CE model that emphasizes the use of evidence in educating students within our discipline. ${ }^{6}$ Fig. 2 displays the model. In developing the model, we made several assumptions. First, we assert that clinical education is a form of teaching. That is, we consider professionals who are in the role of mentoring developing clinicians as $\mathrm{CEs}$ because of the importance of their educational contributions to the students' development. Second, we recognize in the conceptualization of this model that clinical education in its highest art form is a highly specialized type of teaching, with an outcome of independence in clinical practice/decision-making for the student clinician. Thus, to address a missing clinical education link and to emphasize the importance of clinical teaching in our discipline, we created this new model, which accounts for the knowledge, external evidence, and thinking processes that represent the work of those who teach specifically in the clinical context. We initially conceptualized this model of EBE for clinical education (EBE-CE) in a two-dimensional framework ${ }^{6}$ as represented in Fig. 2.

Since the initial development of the EBE$\mathrm{CE}$ model, ${ }^{6}$ our thinking has evolved to more fully represent the complexity of the CE's knowledge base and the necessary conscious decision-making processes that are continually assessed during the clinical process. In an ideal situation, the $\mathrm{CE}$ providing clinical education implements the model effortlessly: working with the student seamlessly through multiple decisions involving best service to the patient, meeting the needs of the student, and effectively meeting any other needs of the CE. However, we assert that this is likely more complicated than it appears. A variety of factors may be present in a given interaction of which the $\mathrm{CE}$ is not fully conscious (e.g., patient factors, level of student preparation for the session), thereby affecting the seamless implementation of the model.

In this new EBE-CE model, depicted in Fig. 3, we see the $\mathrm{CE}$ represented in the middle of a multidimensional model, working 


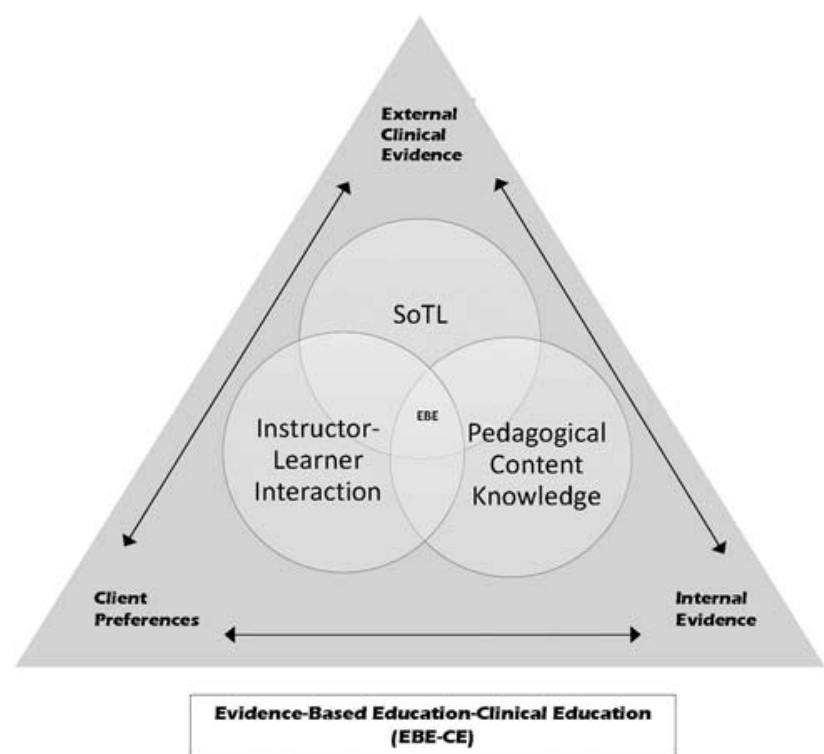

Figure 2 Evidence-based education-clinical education (EBE-CE). ${ }^{6}$ SoTL, scholarship of teaching and learning.

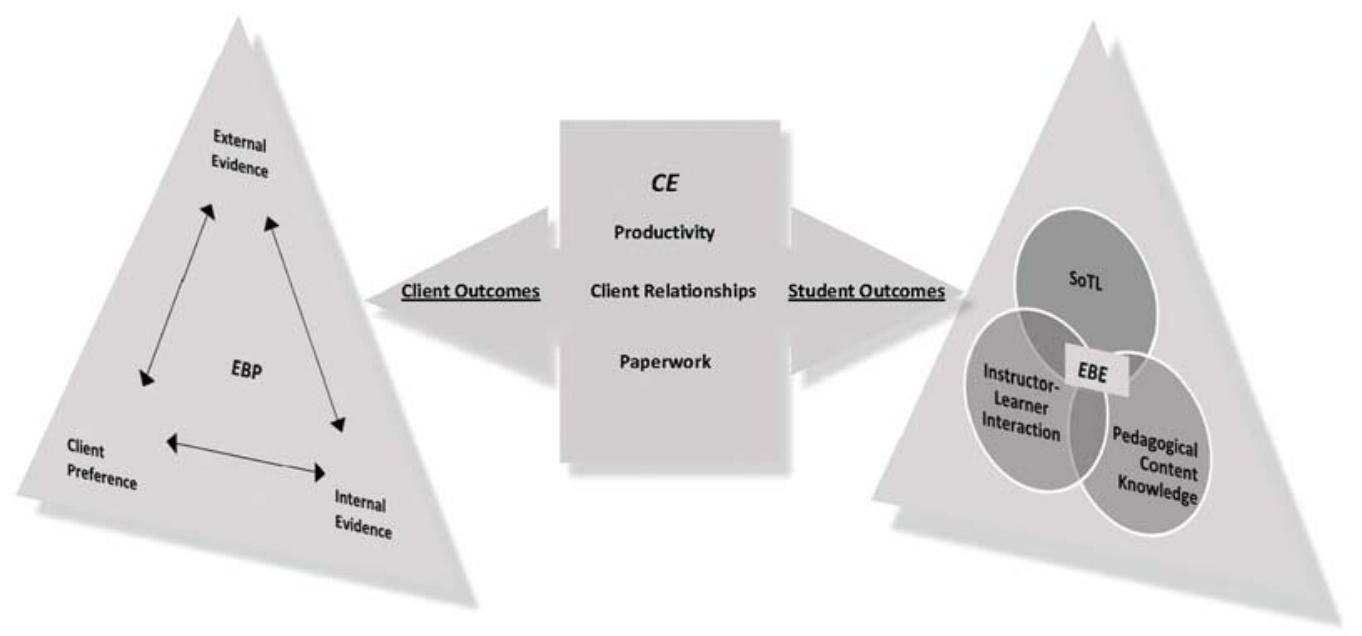

Evidence-Based Education-Clinical Education Model (EBE-CE)

Figure 3 Evidence-based education-clinical education model—updated (EBE-CE). EBP, evidence-based practice.

to balance their EBP knowledge for patient outcomes, on the one hand, and their EBE knowledge for student outcomes, on the other hand. Additionally, the CE must keep in mind the demands of their own position and practice, including productivity, paperwork, and patient/ family relationships. In this new model, we present the basic principles of $\mathrm{EBP}$ on the left and the core of EBE on the right. The middle of the figure represents the complex nature of the relationships for the $\mathrm{CE}$. In this case, the $\mathrm{CE}$ is monitoring the needs of "both sides" with the $\mathrm{CE}$ in the middle. This middle space represents other needs the $\mathrm{CE}$ must consider with every patient and student interaction. As such, the middle is what we refer to as hidden and critical for many CEs in that it often involves factors that are not readily acknowledged, and that may not always be consciously considered during the patient and student 
interactions. Acknowledgment of the role of the $\mathrm{CE}$ in the process of balancing all three sets of needs has been historically overlooked and, thus, likely has been devalued. Current education for the CE to continue to develop skills in these areas is slowly growing. However, many training opportunities focus on broad categories of ethics, relationships, and clinical process. This is evident from the training available by the ASHA and the Council of Academic Programs in Communication Sciences and Disorders (CAPCSD). Both of these groups have produced white papers supporting the education of CEs as well as providing educational resources for CEs. ${ }^{7-9}$ Though the resources are very useful, there is a more granular level to consider in clinical education, as displayed in Fig. 3. In the subsequent sections, we outline these factors, acknowledging that there may be other hidden factors, dependent on the CE's environment. We then propose how future training may be shaped for the CE.

\section{HIGHLIGHTING PRIMARY HIDDEN CHALLENGES IN THE CLINICAL EDUCATION MODEL}

As previously mentioned, it is impossible to address every potentially hidden factor that may be operating in a given training opportunity for a student. However, we discuss a variety of these challenges below to demonstrate their importance-even if they remain unspoken during the clinical encounter.

\section{Patient Complexities}

Patients can present with complex diagnoses, behaviors, personalities, and other needs. For example, experienced clinicians know that some patients can present with a single diagnosis or a myriad of diagnoses that are challenging not only from a medical perspective but for environmental and psychological reasons as well. These factors can complicate both assessment and treatment. No two patients are alike and it is incumbent upon the $\mathrm{CE}$ to consciously consider the EBP model in determining a best approach in the clinical context. As we consider the EBE-CE model, patient complexities should be discussed with students as the $\mathrm{CE}$ moves through the decision-making process. Additionally, working with patients to prioritize their particular needs can be a valuable learning experience for students. Effective CEs will model their conscious decision-making processes and their conversations with patients/families for students in an effective and purposeful way, to foster student learning.

\section{Student Complexities}

Students present with a variety of unique needs as well. Everyday events of managing such things as living on their own, juggling school courses along with practicum, working to make ends meet, and life events that occur while developing into independent adults can affect how a given student presents on any given day. Additionally, students may demonstrate preferences for how they acquire knowledge and what level of risk they are willing to take while learning the clinical process. For instance, some students will prefer to observe for considerable periods of time, whereas others may be willing to engage in the clinical environment immediately. This type of learning preference could be related to factors such as previous experiences and risk aversion. Students who come to the clinical education process with direct or indirect experience related to that environment may be comfortable diving into learning quickly if they can relate the work to a past experience. However, for students who are engaging in a clinical environment for the first time, the experience may require a fair amount of support. The willingness to engage in risk may be internal to the student and may intersect with previous experiences in unpredictable ways. These factors can be considered through Anderson's continuum, in which direct supervision is considered on one extreme of the model, moving to collaborative supervised practice as the clinician's skills grow over time. ${ }^{10}$ In this case, the $\mathrm{CE}$ is responsible for gauging students' needs to move the student through an experience that leads to independence.

In addition, patient complexities can present a "real-world" opportunity for the student, while simultaneously presenting challenges during the assessment or treatment process. Sometimes, the CE may be aware of more efficient means to move the student through 
the clinical education process. However, the $\mathrm{CE}$ carefully weighs the learning opportunity for the student in the moment to determine how much of the challenge to "solve" for the student and how much experiential learning is required for the student to leave the experience with meaningful learning.

\section{Needs of the Clinical Educator}

Another set of hidden factors that have not previously been fully accounted for are the needs of the $\mathrm{CE}$. The $\mathrm{CE}$ is working in an environment where demands have increased over the past decade. Clinicians report that productivity requirements are very important in their workplace setting. ${ }^{11}$ CEs may be challenged to maintain a certain amount of billable time each day, independent of the presence of a student clinician and the student's needs. This can be extremely challenging, in that in the field of communication disorders, it is rarely appropriate to adopt a "see one, do one" approach, in which the student clinician observes a session and then is assumed ready to have the case turned over to them for ongoing services. Instead, CEs are more likely to slowly hand-off cases to students to make certain that the student is able to handle the most important aspects of nuanced care. All of this occurs in a context of documentation expectations. Most environments have strict requirements for documentation, typically linked to the billing process. Regardless of student placement, the $\mathrm{CE}$ is ultimately responsible for documentation in the cases they manage.

Additionally, it is important to consider the fact that CEs are rarely offered an incentive to work with student clinicians in the first place. Instead, they accept the challenge of working with student clinicians as a way to "pay it forward" in the discipline, possibly with little additional support from their facility or the student's college or university. Some employers may also require $\mathrm{CEs}$ to take on student or clinical fellow supervision as a condition of employment (without additional incentives). Given the demands of an already full workday relative to providing services and completing documentation, adding the obligation of clinical education for a student or new clinician can be challenging. Effective CEs have to be ex- tremely well organized to manage the time demands, potential conflicts, and unforeseen events that inevitably occur when taking on the responsibility of teaching.

\section{Patient and Family Relationships}

Finally, there are factors to consider within the clinician-patient therapeutic relationship itself. The CE may have developed relationships with the patients and families they serve prior to the arrival of the student in the clinical context. This can pose a unique challenge for the $\mathrm{CE}$ because of the need to support this relationship within the context of the student placement. Students come and go; however, the patients and their families likely remain.

\section{USE OF THE EBE-CE MODEL}

The EBE-CE model has value in that it allows us to first make evident the factors that must be thoughtfully managed and balanced by CEs in the process of meeting the needs of all parties, thereby creating an opportunity to consciously work through challenges. There are resources available from organizations such as ASHA and CAPCSD for learning about multiple elements of EBE. However, these resources may not entirely address the hidden factors that arise, especially for new CEs. By recognizing these factors, we are able to suggest mechanisms for improvement of the entire clinical education process. We also create the opportunity to structure future research that will foster the best EBE-CE in CSD going forward.

\section{EBE-CE Model Utility: Improving the Future of Clinical Education}

We contend that there are three main values to consider in the EBE-CE model (Fig. 3): (1) heightening reflection on practice; (2) improving the reliance on the body of evidence that is currently available; and (3) shaping the future of ongoing research into the clinical education process to improve our knowledge base. As a first step, it is valuable to consider the individual CE's level of professional development and commitment to the work of supervising. Not all CEs receive extensive formal training in the 
methodology of clinical education. At the time of this publication, there is a requirement for CEs to complete 2 hours of formalized learning prior to providing clinical education to student clinicians and clinical fellows. ${ }^{12}$ Formal training could be delivered as part of the higher education process, an element of a CSD degree program, or in the form of continuing education units, such as those offered by CAPCSD and ASHA. However, we acknowledge that not all CEs have the same level of learning, expertise, and experience with the clinical (EBP) process or the supervisory process (EBE-CE). Therefore, in the sections that follow we apply a SoTL framework to the discussion of CEs, their knowledge base, and their future professional development.

\section{Considering the SoTL Framework}

Clinical education is a highly specialized form of teaching. This teaching represents the intersection of student knowledge and skill and can be conceptualized using a framework proposed by McKinney. ${ }^{13}$ The framework includes the concepts of good teaching, scholarly teaching, and scholarship of teaching and learning to address the various levels of professional development activity seen in higher education in general. Fig. 4 is a visual representation of McKinney's work which demonstrates the hierarchical nature of this framework. It can be easily applied to the work of CEs, because of the close link between clinical education and higher education. While McKinney suggested that SoTL is primarily classroom-based, we would argue that as clinical education takes place in a wide variety of settings,
SoTL literature regarding clinical education can and should be focused on the process of teaching and learning in specific clinical contexts to make this form of teaching evidence-based as well. In the following sections, we will discuss the potential professional development of CEs through the combined lenses of the EBE-CE and the McKinney models.

\section{GOOD CLINICAL EDUCATION}

At the most basic, straightforward level, good clinical education "promotes student learning and other desired student outcomes." ${ }^{13}$ At a minimum, we assert that anyone who engages in clinical education, whether as a focal point of their job or as a new isolated experience that they have never tried before, shares the goal of having student clinicians learn and develop their clinical skills. It is important to note that individuals can be very effective teachers without formal education and/or knowledge of theories of teaching. ${ }^{14}$

Some CEs may be new to the process and find themselves asking broad questions such as:

- Where do I begin?

- How do I create the best experience for a student?

These questions place the $\mathrm{CE}$ in the "good clinical education" portion of the model depicted in Fig. 4. Parallel to McKinney's good teaching, the EBE-CE model could prove to be particularly helpful for the new $\mathrm{CE}$ who is weighing the options of accepting a student into their practice. Often new CEs will state that they are uncertain where to begin, as they may not recall their own

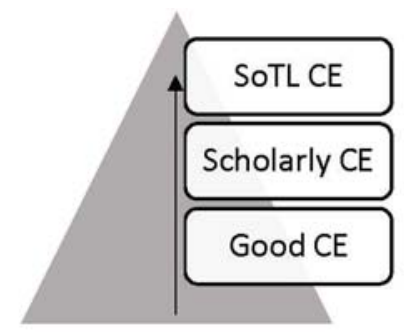

EBE-CE model for professional development (visual representation based on DeRuiter \& Ginsberg, 2019; McKinney, 2007)

Figure 4 Evidence-based education-clinical education (EBE-CE) model for professional development. ${ }^{13}$ 
process of learning to become independent practitioners. Our model provides an excellent starter for the conversation. Although the $\mathrm{CE}$ may have fears, the EBE-CE model breaks down the competing demands and creates a conversational space for the university clinical coordinator to discuss the complexities and rewards of serving as a $\mathrm{CE}$. The model also supports principles of "best practice" because it encourages the $\mathrm{CE}$ to consider both EBP (likely a very familiar concept) and EBE (perhaps a newer content area for the $\mathrm{CE}$ ). The model could also be used when considering complex teaching and learning cases in clinical education. It is important for the $\mathrm{CE}$ to have a framework to make positive decisions about where to allocate their limited resources.

\section{Scholarly Clinical Education}

As CEs move beyond the basic goal of having student clinicians learn and develop their clinical skills, and as CEs start to refine and advance their own skills, they move toward scholarly clinical education. In CSD terms, clinical education at the level of scholarly teaching means being evidence-based educators and clinicians. CEs who are practicing at this level are looking to the SoTL literature that can inform them about best-practices for achieving the best student outcomes, in addition to being knowledgeable about the literature that supports clinical EBP. Scholarly, CEs have an awareness of the relevant literature that will help them make appropriate educational decisions, using $\mathrm{EBE}$, as well as patient-oriented clinical decisions. The literature may come from within CSD or from related fields, such as medical education and teacher education. They may use this evidence to consider new supervisory methods, discuss clinical education challenges with colleagues, or to be purposeful in their reflections on practice to shape improvements. ${ }^{13}$

These CEs have experiences that may lead them to questions such as:

- How can I obtain the best outcomes for my patient in the context of clinical education?

- What data exist for the methods I am using with the student in my clinic?
- Could we teach clinical writing in a way that creates efficiencies in the process, thereby increasing the capacity for student education?

Often, clinicians and educators alike are driven to consult the research to solve a problem that has confounded them. For instance, this occurs when the clinician cannot figure out how to help the pediatric patient move past a plateau in their acquisition of morphemes; so, they turn to the appropriate EBP research to see what has been identified by researchers to help them be more effective clinicians. Educators often struggle to help students learn how to become more effective in clinical problem-solving; so, they seek guidance from the EBE research to help them find a way to be more effective in their teaching. CEs may seek out EBE-CE resources to help them solve a problem that their good clinical education skills have not been able to solve, in line with McKinney's scholarly teaching construct. Finding a teaching strategy, such as a way to improve clinical writing, when the most common approaches have not succeeded may lead the $\mathrm{CE}$ to the literature to see what others have found to be helpful. CEs who are answering these questions are represented in the middle of McKinney's framework of SoTL, ${ }^{13}$ as displayed in Fig. 4.

\section{SoTL Clinical Educator}

The highest level of engagement with clinical education is engaging in SoTL. ${ }^{13,15,16}$ At this level, CEs are conducting research in a "process by which teacher-scholars [CEs] prepare for their inquiry, inquire, and explore what it all means." ${ }^{17}$ In other words, much as the clinical researcher investigates the clinical outcomes of a particular treatment approach, CEs can conduct research regarding the educational outcomes of a particular model of clinical education to contribute to the body of literature that informs scholarly practice.

CEs who are motivated to contribute to the body of evidence in clinical education may ask questions such as:

- How do I move forward with researching the methods I am using as a CE? 
- How do I disseminate what I have learned as a CE?

For those CEs who choose to participate in SoTL for the purpose of gaining understanding about the effectiveness of clinical education, it is important to keep a few key concepts in mind. SoTL work should always be consistent with and acceptable for our own discipline; it should be publicly disseminated; and it should be subjected to the scrutiny of our peers. ${ }^{16,17}$ There is inherent value to the $\mathrm{CE}$ conducting SoTL research, as they are likely to find insights or answers to challenging questions related to clinical education practices. However, there is additional value in disseminating this research to serve as a resource to guide other CEs who are practicing scholarly clinical education. CEs who are operating as SoTL CEs are represented at the peak of McKinney's conceptual model, displayed in Fig. 4.

\section{USING THE EBE-CE MODEL TO DRIVE THE SOTL CLINICAL EDUCATOR}

There are various aspects of the EBE-CE model that can serve to drive potential research questions of the CE engaging in SoTL. For example, the $\mathrm{CE}$ can look to the EBE-CE model and contemplate how to achieve a positive clinical outcome for an overly aggressive, verbally inappropriate patient with traumatic brain injury (TBI) while also achieving a positive learning outcome for the shy and timid student clinician who is overwhelmed by the patient's inappropriate verbalizations during therapy. By reflecting on the challenge, the $\mathrm{CE}$ demonstrates good clinical education. However, if after contemplation, the $\mathrm{CE}$ needs more information, the $\mathrm{CE}$ would engage the student with the evidence base regarding which aspects of TBI are causing the clinical presentation, while also addressing any personal factors of the student. These actions are consistent with the scholarly $C E$ stage. Using the literature as a source of external data facilitates an opportunity for the $\mathrm{CE}$ and student to engage purposefully for specific patients or for particular disorder types. If the $\mathrm{CE}$ determines that there is inadequate literature to guide a clinical education decision or identifies a better approach to try, the CE may choose to systematically collect data and engage in research regarding the clinical education process. These actions are consistent with practices of SoTL, in that they contribute to the growing body of literature that informs clinical education. As our evidence base grows (both clinically and from a clinical education standpoint), decisions can become more datadriven, with conversations referencing supporting literature. This professional development/ growth creates a cycle by which there is a growing body of evidence being created by the very professionals who rely on it. ${ }^{17}$

\section{CONSCIOUS CLINICAL EDUCATION AND THE EBE-CE MODEL}

The EBE-CE model is useful as we conceptualize research to practice. The EBE-CE model initiates and continues a cycle of questioning, investigating, and informing our literature to flesh out the evidence available to CEs for use on all levels. ${ }^{17}$ It is incumbent upon us as EBP disciplines to apply the same level of rigor and scrutiny to our classroom and clinical education as we do to our clinical practice. By relying on an evidence-based model for clinical education, we can provide support for CEs within any stage of their professional development. Additionally, by using the SoTL literature, as well as contributing to it, CEs can decrease frustration and improve learning outcomes of students. Adoption of this model opens the door to greater understanding, professional development, and research opportunities that truly link our clinical education and training institutions and practices together in a conscious manner for improved outcomes for all involved.

\section{FINANCIAL}

No relevant financial relationships exist for either author.

\section{NONFINANCIAL}

Both authors serve on the editorial board of Teaching and Learning in Communication Sciences and Disorders, a journal that publishes related content. No other relevant nonfinancial relationships exist for either author. 
CONFLICT OF INTEREST

None declared.

\section{REFERENCES}

1. Standards for Accreditation of Graduate Education Programs in Audiology and Speech-Language $\mathrm{Pa}-$ thology. Council on Academic Accreditation in Audiology and Speech-Language Pathology; 2017. Available at: https://caa.asha.org/wp-content/ uploads/Accreditation-Standards-for-GraduatePrograms.pdf. Accessed February 21, 2020

2. Evidence-Based Practice in Communication Disorders [Position Statement]. American Speech-Language-Hearing Association; 2005. Available at: www.asha.org/policy. Accessed February 21, 2020

3. Report of the Joint Coordinating Committee on Evidence Based Practice. American Speech-Language-Hearing Association; 2004. Available at: https://www.asha.org/uploadedFiles/members/ebp/ JCCEBPReport04.pdf. Accessed February 21, 2020

4. Ginsberg SM, Friberg JC, Visconti C. Scholarship of Teaching and Learning in Speech-Language Pathology and Audiology: Evidence-Based Education. San Diego: Plural Publishing, Inc.; 2012

5. Shulman LS. Knowledge and teaching: foundations of the new reform. Harv Educ Rev 1987;51 (01):1-22

6. Ginsberg SM, DeRuiter M. Research and the clinical education and supervision process. In: McCrae ES, Brasseur JA, eds. The Clinical Education and Supervisory Process in Speech-Language Pathology and Audiology. Thorofare, NJ: Slack; 2020:411-426

7. Knowledge, Skills and Training Considerations for Individuals Serving as Supervisors [Final Report, Ad Hoc Committee on Supervision]. American Speech-Language-Hearing Association; 2013. Available at: https://www.asha.org/uploadedFiles/ Supervisors-Knowledge-Skills-Report.pdf. Accessed February 21, 2020

8. A Plan for Developing Resources and Training Opportunities in Clinical Supervision. American Speech-Language-Hearing Association; 2016. Available at: https://www.asha.org/uploadedFiles/
A-Plan-for-Developing-Resources-and-TrainingOpportunities-in-Clinical-Supervision.pdf.

Accessed February 21, 2020

9. White Paper: Preparation of Speech-Language Pathology Clinical Educators. Council of Academic Programs in Communication Sciences and Disorders; 2013. Available at: https://wordpressstorageaccount.blob.core.windows.net/wp-media/ wp-content/uploads/sites/1023/2019/06/WhitePaper-Prep-of-SLP-Clinical-Education-FinalApril-11-2013.pdf. Accessed February 21, 2020

10. Anderson JL. The Supervisory Process in Speech Language Pathology and Audiology. Austin, TX: Pro-Ed; 1988

11. 2017 SLP Health Care Survey Summary Report: Number and Type of Responses. American Speech-Language-Hearing Association; 2017. Available at: https://www.asha.org/uploadedFiles/ 2017-SLP-Health-Care-Survey-Summary.pdf. Accessed February 21, 2020

12. 2020 Standards for the Certificate of Clinical Competence in Speech-Language Pathology. American Speech-Language-Hearing Association; 2018. Available at: https://www.asha.org/certification/2020-SLP-Certification-Standards. Accessed February 21, 2020

13. McKinney K. Enhancing Learning through the Scholarship of Teaching and Learning: The Challenges and Joys of Juggling. Bolton, MA: Anker; 2007

14. Smith RA. Expertise and the scholarship of teaching. In: Scholarship Revisited: Perspectives on the Scholarship of Teaching: New Directions for Teaching and Learning. Vol 86. San Francisco, CA: Jossey-Bass; 2001:69-78

15. Boyer EL. Scholarship Reconsidered: Priorities of the Professoriate. San Diego, CA: Jossey-Bass; 1990

16. Shulman LS. Introduction. In: The Course Portfolio: How Faculty Can Examine Their Reaching to Advance Practice and Improve Student Learning. Sterling, VA: Stylus; 1998:5-12

17. Bernstein J, Ginsberg SM. Toward an integrated model of the scholarship of teaching and learning and faculty development. J Cent Teach Learn 2009; $1: 41-55$ 